\title{
Design and Application of Experimental Teaching System Driven by Big Data Technology in Economics and Management Majors
}

\author{
https://doi.org/10.3991/ijet.v15i11.12997 \\ Qiang Liu, Liwen Zeng $\left({ }^{-}\right)$ \\ Guangdong University of Finance \& Economics, Guangzhou, China \\ zlw@gdufe.edu.cn
}

\begin{abstract}
This paper explores the application of big data technology in experimental teaching system to solve the problems in managing and storing experimental data, including data loss, difficult to quantify teaching processes and feedback, and the lack of foundations for curriculum design of experimental teaching. By proposing a comprehensive system for experimental teaching, analyzing the key points of this system, and expounding the functional planning and the technical routes of this system, this paper outlines a practical path to establish an experimental teaching system driven by big data for students majoring in economics and management. Additionally, we use a real experimental teaching system as a case study. The results of this study can not only extend the knowledge in this research area, but also provide important implications for other universities to enhance the students' various abilities targeted.
\end{abstract}

Keywords - Big data technology, experimental teaching, economics and management

\section{Introduction}

In todays' universities, a number of digital tools, devices and platforms are available to education professionals. They can rethink and reshape educational and assessment practices, methods and environments to be the best fit for their students, with less ties to traditional teaching and grading methods and practices ${ }^{[1][2]}$. Utilization of novel technologies and methodologies, along with innovative thinking have brought changes to education, creating learning opportunities through activities that would not traditionally be considered educational for the development of social, personal and creative skills [3][4][2]. Under the direction of the "Guidelines for the Development of the Ten Years of Education Informatization Program" (2011-2020), the construction of higher education informatization teaching in China has continued to develop with regards to the management and research of teaching in universities. Therefore, the application of information technology in teaching has received widespread attention from scholars. Experimental teaching is a widely used method for teaching undergraduate students majoring in economics and management, thereby making it be a very important part of the 
informatization of education ${ }^{[5]}$. However, many problems still exist in the current process of experimental teaching, including the difficulties of managing and storing experimental data, the problem of data loss, difficult to quantify teaching processes and feedback, and the lack of foundations for curriculum design of experimental teaching. Then big data technology is applied to provide solutions to the above problems. That is why to build a comprehensive platform for experimental teaching driven by big data has been a new trend. Big data is a kind of value outlook and methodology which has the potential to play an important supporting role in improving the quality of education. It is capable of ensuring education's fairness and reforming pedagogical methods.

In the teaching process, it is fairly common for teachers in universities to neglect the practical aspects of teaching, even though these practical teaching are critical to the improvement of students' abilities. This is particularly true for those teachers who teach undergraduate students majoring in economics and management. In order to provide better practical teaching for these students, most universities offering degrees in economics and management have reformed their teaching methods by building and introducing new platforms for experimental teaching, which could help to improve the practical abilities of the students. Especially by applying big data, these innovative experimental teaching platforms not only could support effective teaching but also reform the basic understanding of practical teaching. Being guided by an information-based approach to education and supported by advanced education technologies, massive timely data can be utilized to analysis students' behaviors and improve their practical abilities in a targeted manner, especially students' abilities in innovation and entrepreneurship. Thus, experimental teaching systems using big data technologies can make education in economics and management major more effective. For this reason, we argue that universities should build content systems driven by big data for practical and experimental teaching. To ensure the teaching quality of experimental teaching, a systematic software and hardware platform need to be built well. For the universities which focus on economics and management major, it is important to independently develop a comprehensive information platform for the experimental teaching driven by big data because of the teaching requirements of combining theories with practices together. This platform would significantly contribute to enhance students' various abilities, especially abilities in innovation and entrepreneurship, and provide comprehensive experimental teaching across a range of different majors ${ }^{[6]}$. In this study, we work with the design and application of experimental teaching system driven by big data which allow record and analyze students' learning data for offering best fit teaching.

\section{The Processes of Establishing Experimental Teaching System}

\subsection{Characteristics and basic functions of experimental teaching system driven by big data}

Over the past decades, data has been more visible, accessible and usable. A very large number of data are generated every second, which can provide detail, accurate, comprehensive and timely information to us. According to Gartner's definition, circa 
2001 (which is still the go-to definition), big data refers to data that contains greater variety arriving in increasing volumes and with ever-higher velocity. It can be used to analyze and reflect individuals' thoughts, as well as their behaviors and emotions. By collecting and processing big data, it is possible for people to make more precise decisions. It also provides greater insight and have more abilities to optimize processes in lots of fields, for example, education. Experimental teaching platforms driven by big data allow for collection and storage of massive data. These data include various kinds of structured, semi-structured and unstructured data, such as data related to the teaching processes, student experiments, student management, and system platform logs. In fact, everything happens on the experimental platform, including both teachers' and students' behaviors, can be recorded by data. After cleaning and processing, these massive data can provide information regarding decision-making and behaviors to pedagogical researchers, managers in experimental teaching, and students who participant experimental courses. Therefore, it may have benefits for teaching, scientific research, personnel training and production integration ${ }^{[7]}$.

Simulation practices using experimental teaching platform driven by big data has gradually been a novel teaching trend in universities. They are different from traditional experimental teaching in many ways. An effective experimental teaching system is composed of following aspects: multiple software elements, multimedia course resources, a sand table resource database, a computer network, and an economic management database. In this system, practical and simulative approaches are combined together. Electronic and manual means complement each other. Modern and traditional methods are interconnected. In addition, different methods are also involved in experimental teaching, for example, the situational teaching method, the inquiry teaching method, the method based on teaching games, and the experiential teaching method. Virtual simulation classrooms and three-dimensional tangible classrooms can also be integrated into this system well. By using the experimental teaching system to give enterprise simulation training courses to students, it become possible to combine theories with practices in professional education. One of the attributes of experimental teaching system driven by big data is that this system can allow thousands of undergraduate students with different major to take part in enterprise simulation training courses together. These students in courses are involved in the operation of simulated enterprises (e.g. external service management institutions, economic organizations, and manufacturing companies). Under the guidance of professional teachers, according to the prescribed rules and processes, students carry out large-scale, complex and dynamic operations in a simulated market environment. These simulation practices help to strengthen students' understanding of enterprises' actual operations and enhance the abilities to apply professional knowledge to operations.

\subsection{Technical route and functional planning of experimental teaching system driven by big data}

Big data can be used to do research and analysis. Based on the course and behavioral data regarding teaching and learning developed on business platforms (e.g. experimental teaching platform, the teaching resource platform, the laboratory management 
information system) and the relevant daily behavioral data of research objects (such as students and teachers) from the university's digital campus, we can analyze teachers and students' behaviors and abilities more accurately and comprehensive. To transmit, store and process the data generated by the mobile learning terminal, a wireless network is also used. The technical route of experimental teaching system driven by big data is as follows:

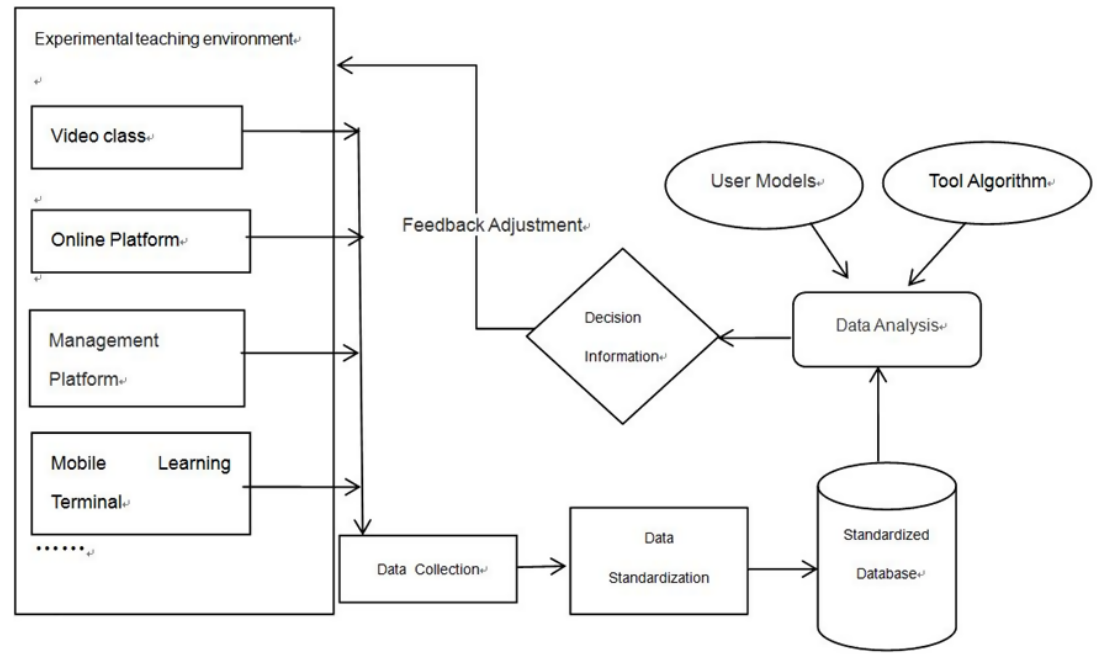

Fig. 1. The Technical Route of the Experimental Teaching System

To establish an effective experimental teaching system driven by big data, several specific steps of functional planning are involved.

Step1: Construct a data warehouse system: This initial step also helps to solve the problems regarding data archiving and management problems that exist in the current experimental teaching system. ${ }^{[8]}$ Figure 2 shows the processes of extracting, transforming and loading data. The big data platform can be expanded online easily, it not only can support different business systems for experimental teaching, but also extract structured, unstructured and semi-structured data efficiently. By deploying a flume agent on each website log server, the data of external internet website logs (which are distributed across multiple website log servers and stored on HDFS) can be collected dynamically and in real time. ${ }^{[9]}$ For example, the system may rely on an e-commerce platform and a stock platform to obtain data regarding transactions. Big data provided by FTP teaching resources or some cooperative units, as well as by the school network center and library on the experimental teaching platform, can also can be obtained regularly through FTP / HTTP. Through "Sqoop," various business databases can be synchronized to HDFS. For example, the experimental teaching management platform and laboratory information management system combine "sqlserver," "Oracle," and "mysql." In this way, by using Flume, both semi-structured and unstructured data (such as, students' daily behavioral data and training process data) can be synchronized from the database to HDFS in real time. Additionally, this big data platform also provides an interface for 
collecting some data that is entered manually (this, for example, allows for the collection of data concerning teaching processes that cannot be temporarily covered by certain means of information.

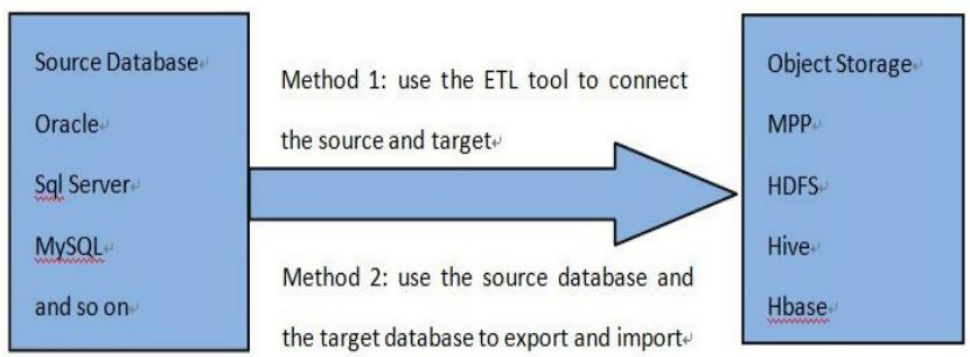

Fig. 2. Data Flow in the Big Data Platform

Step 2: Construct a platform for managing and analyzing big data: Then a platform is needed to manage the data by carrying out the processes of data extraction, cleaning, conversion, verification, and loading. This platform helps to complete the process of extracting internet data, business data and equipment data from the data sources and moving them to the target data warehouse. It also provides a means for storing data from those sources for medium and long terms. The platform can be roughly divided into a few different layers: the data application layer, the data service interface layer, the data storage sharing layer, the data access management layer, the data preparation layer, and the data source layer ${ }^{[10]}$. Specifically, the data application layer includes all kinds of business applications. The original data, which may be difficult to use, is specialized, examined and analyzed in a unified way. Through this process, original data are transformed into orderly and valuable data. On this basis, the types of applications can be more extensive and the information resource services can be constructed more conveniently and efficiently. Value can be excavated much more effectively and deeply from both unstructured and structured data. The data service interface layer helps to provide a unified standard data service and a high-performance service interface for the upper application layer. The data storage management layer is built for storing the big data that is generated and collected by the platform. The data management layer realizes the integration of the Hadoop platform and the MPP database cluster. It integrates hive, MapReduce, multi copy, column storage, intelligent indexing and other processing technologies to store and manage the big data generated by the resources. The distributed storage systems of HDFS, HBase and Hadoop are used to store and manage unstructured and semi-structured big data. The forms of data recorded might include audio and video, internet materials and more. The MPP database cluster is used to store and manage high-value and high-density structured data in the style of a data warehouse ${ }^{[11]}$. The data access management layer helps to complete the process of transforming the various types of data (internet data, equipment data, and more) from the data source to the target data warehouse. This process involves completing the data extraction, as well as cleaning, converting, verifying, loading and other forms of processing. It uses traditional ETL to process a small part of the structured 
data, and uses cloud ETL (Hadoop) to process massive amounts of unstructured, semistructured, structured data. The data preparation layer is built for collecting and temporarily storing all the data from the source system through bridging, importing, exporting and more by way of ETL. It operates in accordance with the data format of the source, which is assessed during the period of data inspection and as part of ETL data processing. The data source layer provides data for the whole system, including the business system for internal experimental teaching, the integrated application system, the external internet data and the social resource data. In order to ensure the security of data source, the system does not extract data directly from the data source system, but through the data preparation layer as an intermediary.

Step 3: Analyze and process big data: The first thing need to do for analyze and process data is to collect data. The front-end system collects and summarizes all kinds of data including internet data and equipment data from the source system. Then, these data are temporarily stored according to the source data format. This processing step helps to prevent data from any interference with the source system, and prepare suitable data for inspection and ETL processing. Data on the ETL platform can be divided into unstructured, semi-structured and structured data according to their different sources. In order to process these different types of data efficiently on the ETL platform, the platform extracts data from the front-end system, then cleans, converts and verifies them. Subsequently, both unstructured data and the Meta data / index of massive semistructured data are imported into the data warehouse. The difference is that the unstructured data with low value density are stored in the Hadoop system, while structured data with high value density are located in the MPP database cluster. Specifically, the Hadoop system is responsible for storing and managing the massive unstructured and semi-structured data. However, storing and managing of structured data need to be completed in MPP database cluster. Furthermore, in order to deal with distributed computing and non-relational processing, the MPP database cluster is used to back up the data. The MPP database completes the construction of the data warehouse, and performs complex associated queries and analysis on all the data. It also synchronizes the data to the Hadoop system for non-relational processing and to back it up. In addition, the version control and management of the data are both taken care of by the fact that the data source is backed up by the front-end system. In the case that there is a data refresh in the source system, the data can be extracted again or traced back to its original form. After collecting and dividing, data then can be cleaned. In order to remove duplicate records, standardize and unify the business data, replace and remove invalid data, it is necessary to clean and transform the data from different sources to meet the standards and definitions of the experimental teaching platform. As such, it is necessary to provide a variety of data cleaning methods and to remove invalid data, filter and remove duplicate records. To deal with the invalid and duplicate data, null value processing and other methods can be used. By analyzing and processing big data stored in Hadoop system and MPP database cluster, both teachers' and students' behaviors can be observed and demonstrated more precisely and in more detail. 


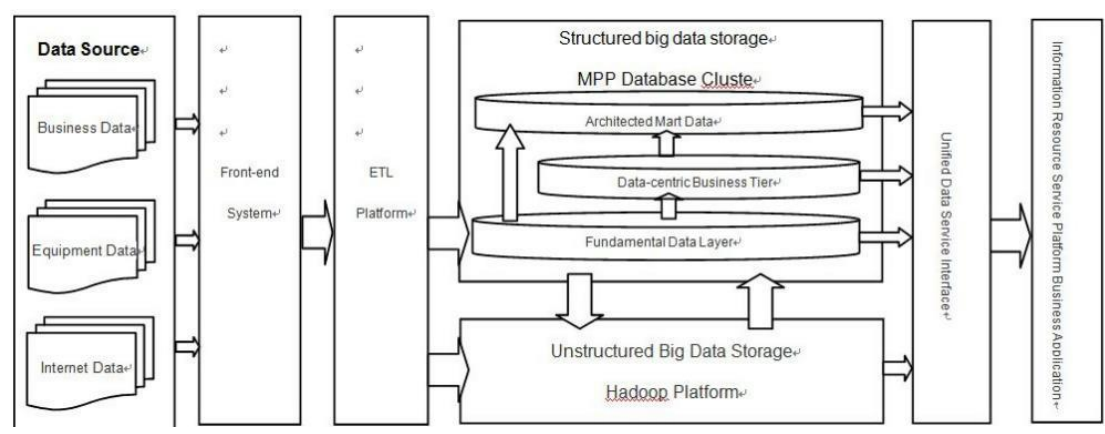

Fig. 3. Data Processing in Platform driven by Big Data

\section{A Teaching Case Study}

In this study, we also use a real teaching course as a case study. Taking "enterprise comprehensive operation simulation" which use experimental teaching system driven by big data as an example, this course is a compulsory experimental course for students majoring in economics and management in Guangdong University of Finance \& Economics, which is a university in China. It creates a business environment through information technology in which the competitive game relationship among consumers, customers, manufacturers and raw material suppliers in the process of enterprise comprehensive operation are highly simulated. Different roles played by students majoring in economics and management collect and analyze the external and internal information of the enterprise, then make decisions that is conducive to themselves. This course is designed to combine theories and practices together in the experimental teaching for undergraduate and graduate students in economics and management major. It is taught by the mode of "main teacher + assistant teacher". Before class, the preview knowledge points are released to students through the online learning platform. At the beginning of class, the preview situation of students is mastered in time through the online test, so that teachers can adjust the teaching progress in time. During the class, the learning resource platform and management platform are utilized to carry out the face-to-face teaching. Through online group discussion, intergroup inspection, doing online game, result submission, and performance evaluation, students' abilities in various aspects can be improved.

During classes, everything happen on the system can be recorded by data. Sorting out these original data in the teaching platform and building data warehouses at multiple levels can help produce high-quality data which can be used to provide external services. Through standard API encapsulation, interface permissions can be provided for third parties in the form of data resource operations, and various applications can be developed. These are critical for the experimental teaching system. Comprehensive experiments for students in economic and management major enable students to learn the ways in which enterprises operate month by month. Students from different majors are also able to learn how to communicate and cooperate as a real team, adapt to different positions and make better decisions because this experimental teaching can give 
students to complete enterprise registration, and make decisions about human resource management, marketing, production management, sales management, investment management, financial management and other businesses events under the simulation situation. The purpose of interdisciplinary experimentation is to try and develop students' entrepreneurial abilities. In addition, the experimental process can effectively use all kinds of teaching and practice data generated through big data technology, therefore, provide a basis for the reform of interdisciplinary experimental courses ${ }^{[12]}$.

This course has been carried out in Guangdong University of Finance \& Economics for nearly 15 years. Through this experimental teaching platform driven by big data, nearly 10000 samples' data, such as log data, experiment report, score sheet, blog speech, teacher evaluation, and library borrowing data, have been analyzed. By doing this, a number of scientific and effective conclusions have been drawn which further make significant contribution to promote the reform of course construction, teaching effect, education measurement, and provide new ideas and paths for the reform of other experimental courses. At present, the teaching experience of using experimental teaching system driven by big data to reform the experimental teaching has been shared with more than ten colleges and universities, and well received.

\section{Discussion}

The construction and exploration of experimental teaching platforms driven by big data technology plays an active role in organizing and constructing content for experimental teaching systems. Students not only needs theoretical courses, but also needs to combine practical courses with theoretical models closely in order to promote and achieve comprehensive abilities. Especially for students majoring in economic and management, it is necessary for universities to provide experimental courses for them because these majors emphasize applying theories into practices. In order to have a positive effects of experimental teaching, it is important to apply a scientific approach into curriculum development, and establish a sound teaching plan and a thorough evaluation system. When constructing syllabus and teaching plans, it is important to design them based on enterprises' needs of employees' abilities. Only in this way, students' abilities can be improved to cater to the needs of human resources market. But, it is not an easy task to evaluate and train students targeted. So we must collect and analyze multi-source data in order to know different students well. Big data technology gives us an approach to realize it because of its power to collect all the data for analyzing and processing. It provides the basis for decision-making with regards to teaching reform. [13] Additionally, traditional courses only rely on a certain final score as the standard to evaluate students' individual abilities. However, in the experimental courses, different aspects of students' behavior, including ability, activeness, and decision-making behaviors, could be recorded by data which can be analyzed to provide more targeted practices. Then, diversified and multi-level practices can help students to recognize their abilities to a full extent and in a timely fashion. ${ }^{[14]}$.

One reason why we need to apply big data technology to experimental teaching is that data loss, processing errors and poor operations are often occurred in the processes 
of using experimental software systems. Big data technology helps to solve these problems. Big data technology has been widely used in public security, social security, finance and other industries. When it is applied into education, like an interdisciplinary experiment, technical problems will be avoided effectively. Another reason to apply big data technology is that we can utilize big data to collect and analyze students' behaviors and give them feedback based on the analysis results. Active collection of learning data, through behavior and interaction during learning activities, and the resulting analytics, offer the potential of gaining actionable insights ${ }^{[15]}{ }^{[16]}$ In traditional experimental teaching, there is no data that records the experimental processes and results. It is difficult to evaluate students' behaviors and performances with quantitative indicators. By using big data, students' behaviors related to company registration, investment and financing, accounting can be collected and analyzed. Thus, the performance and results of students' experimental processes can be comprehensively evaluated to analyze and train the abilities of students. By analyzing data of students' behaviors and their experimental results, early warnings could be generated and transferred to educators to foresee and develop a clear view of students' progress in learning environment. For instance, teachers can predict if a student need professional advises or additional assistance $^{[17]}[18]$ (Drachen et al., 2013; Prensky, 2001). Overall, it will help to provide authentic data of students' learning behaviors and results, thereby enhancing students' pedagogical experience and reducing the cost of teaching. The processes about how big data are applied in experimental teaching system is shown as Figure 4.

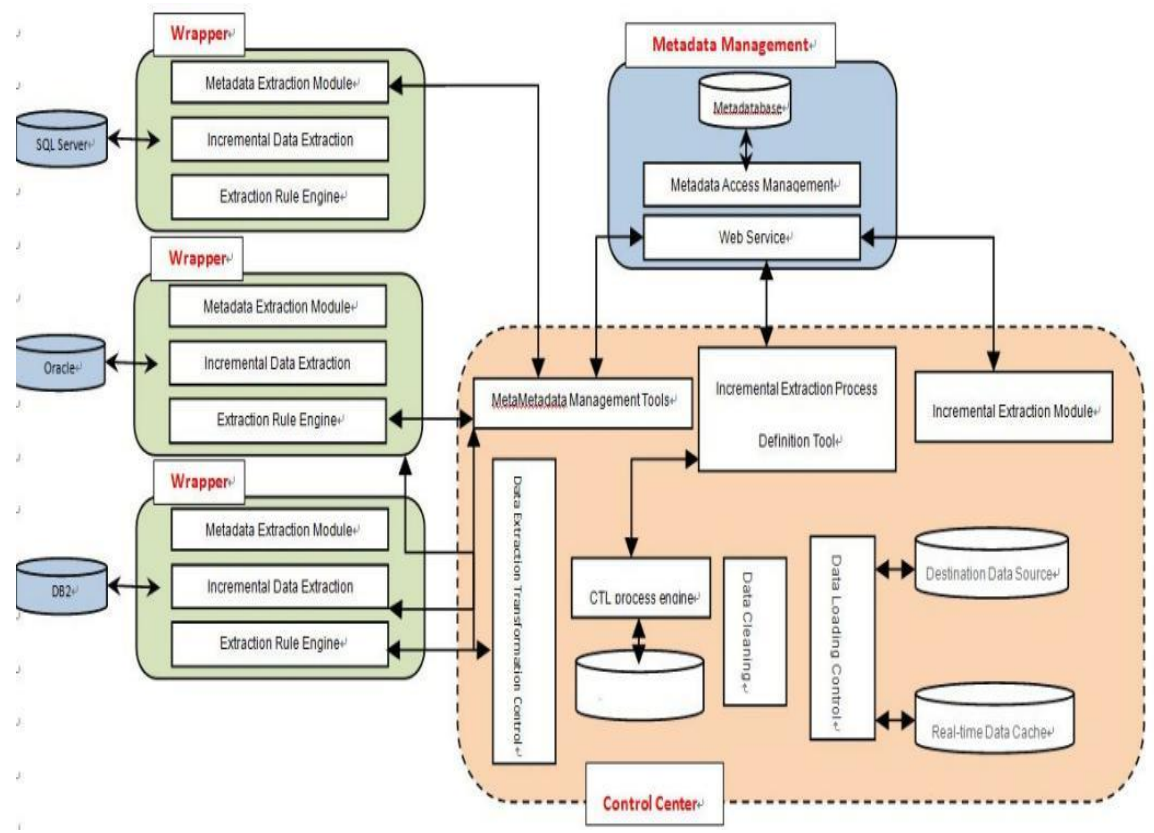

Fig. 4. The Process of Big Data Applications 


\section{Conclusion}

To avoid the problem of data archiving and management in the traditional experimental teaching courses and guarantee the analysis effect of relevant data, it is very important for universities to build a comprehensive system driven by big data for experimental teaching which is provided to students majoring in economics and management. In this system, different kinds of structured, semi-structured and unstructured data, related to teaching processes, student learning experience, student management, and the system's platform log, can be collected and processed. These huge data set data can be used to evaluate and train students targeted after cleaning and processing. In addition, during the experimental teaching processes by using platform driven by big data, we can form a number of standardized achievements which can be radiated, shared and copied and contribute to the new knowledge of experimental teaching .These achievements can give implications to the more detailed explorations in the practicalities of experimental teaching, as well as personnel training, scientific research, and the integration of production and teaching.

\section{References}

[1] McFarlane, A., Sparrowhawk, A., Heald, Y. (2002). Report on the educational use of games.

[2] Vidakis, N., Barianos, A.-K., Trampas, A.-M., Papadakis, St. Kalogiannakis, M., \& Vassilakis, K. (2019). Generating Education in-Game Data: The Case of an Ancient Theatre Serious Game. In B. McLaren, R. Reilly, S. Zvacek, \& J. Uhomoibhi (Eds), Proceedings of the 11th International Conference on Computer Supported Education (CSEDU 2019), 1: 36-43, Heraklion, Crete, https://doi.org/10.5220/0007810800360043

[3] Vidakis, N., Christinaki, E., Serafimidis, I., Triantafyllidis, G. (2014). Combining ludology and narratology in an open authorable framework for educational games for children: The scenario of teaching preschoolers with autism diagnosis. Lect. Notes Comput. Sci. (including Subser. Lect. Notes Artif. Intell. Lect. Notes Bioinformatics) 8514 LNCS, 626-636. https://doi.org/10.1007/978-3-319-07440-5_57

[4] Vidakis, N., Syntychakis, E., Kalafatis, K., Christinaki, E., Triantafyllidis, G. (2015). Ludic Educational Game Creation Tool: Teaching Schoolers Road Safety. In: Antona, M., Stephanidis, C. (Eds.), Universal Access in Human-Computer Interaction. Access to Learning, Health and WellBeing, 565-576. https://doi.org/10.1007/978-3-319-20684-4_55

[5] Qiao, P.X, Li, H.B., Wei, D.Y. (2019). Internet + smart campus: the new form of intelligent campus in the 2.0 era of educational informatization. Education Exploration, 5: 63-68.

[6] Yu, H.F. (2011). Taking ability training as the core, deepening the reform of experimental practice teaching. China Higher Education, 22: 29-31.

[7] Huang, J.Z., Du, B., Zhang, H.Y., Peng, H.M. (2018). Design of Computer Experimental Teaching System through Contests. Research and Exploration in Laboratory, 37(04): 162165.

[8] Wang, F., Yang, L., Guo, H.T., Ji, J.Y. (2016). Exploration of experiment teaching reform for economic and management specialties under the background of big data. Laboratory Science, 19(03): 72-75.

[9] Rocha, D. (2018). Design and implementation of a real-time monitoring tool for power engineering education. Computer Applications in Engineering Education, 1 (26). 
[10] Zhang, J.F., Liu, Q., Li, L. (2018). Application of Hadoop and ETL Technology in video data. Police Technology, 5: 27-29.

[11] Anna, J., Tracy, R., Melissa, B., et al. (2018). Multidisciplinary teams and ICT: a qualitative study exploring the use of technology and its impact on multidisciplinary team meetings. BMC Health Services Research, 18(1). https://doi.org/10.1186/s12913-018-3242-3

[12] Zhang, Y. (2016). Analysis and implementation of storage architecture based on big data [J]. Journal of Suzhou Education Institute, 19(06): 110-111.

[13] Tan, X., Li, H. (2019). Research Front Recognition Based on Multi-source Data Knowledge Fusion Method. Journal of Modern Information, 39(08): 29-36.

[14] Chen, K, Wang, H.B., Liu, H.Y., Xu, Y.Q. (2015). Design of Comprehensive Experimental Teaching System of Computer Network based on Multiple Virtual Platforms. Modern Educational Technology, 25(07): 107-112.

[15] Arnold, K. (2010). Signals: Applying Academic Analytics. Educ. Q. 1, 33.

[16] Elias, T. (2011). Learning Analytics: Definitions, Processes and Potential.

[17] Drachen, A., Seif El-Nasr, M., Canossa, A. (2013). Game Analytics-The Basics. In: Game Analytics. Springer London, London, 13-40. https://doi.org/10.1007/978-1-4471-4769-5_2

[18] Prensky, M. (2001). Digital Natives, Digital Immigrants. Horiz. 9, 1-6.

\section{Authors}

Qiang Liu is deputy director of the Economics and Management Experimental Teaching Center Guangdong University of Finance \& Economics in Guangzhou, China, senior experimentalist, mainly engaged in computer application technology, education technology, and experimental technology research.

Liwen Zeng is the corresponding author. She is an assistant researcher, the section chief of faculty's management office in Human Resource Department of Guangdong University of Finance \& Economics in Guangzhou, China. Her current researches focused on human resource management and higher education management.

Article submitted 2020-01-03. Resubmitted 2020-02-25. Final acceptance 2020-02-25. Final version published as submitted by the authors. 